\title{
EXPLRIMENTAL AND COMPUTED RESULTS FOR FLUID-STRUCTURE INTERACTIONS WTH IMPACTS IN THE HDR BLOWDOWN EXPERIMENT
}

\section{U. SCHUMANN}

\author{
Kernforschungsserstrum Karlsnuhe GmbH, Institut fä Reaktorentwicklung, Projek! Nukleare Sicherheit. \\ HDR Sicherheitsprognamm, Partfach 3640, D.7500 Karlsnhe, Federal Republic of Germany
}

Received 31 August 1982

The HDR experimental facility has been used for several blowdown experiments in order to study fluid-structure interactions and loadings on the pressure vessol internal structures of a ressurized water reactor. We have developed the code FLUX to analyse the motions in the initial blowdown period.

This paper describes a new type of HDR experiment (V34) and compares the experimental results with the FLUX-code results. As novel feature, the core barrel is not rigidly clamped to the vessel as in earlier experiments but supported with gaps such that the core barrel can move freely upwards for about $2 \mathrm{~mm}$ and horizontally for $0.3 \mathrm{~mm}$ at the upper lange. At the lower core-barrel edge, snubbers restict the horizontal motion to about $+1.4 \mathrm{~mm}$ and $-2.8 \mathrm{~mm}$.

The experimental results show that the core barrel is deflected sidewards until it hits the snubber at the lowe: edge and then swings back to hit the opposite snubber. By this some kinetic energy is lost due to plastic snubber deformations. At the same time, the measurements show that the core barrel lifts rather uniformly from its support upwards until it hits the upper constraint. Several bounces up and down are observed until the core barrel becomes fixed probably due to friction from the side.

This situation has been pre- and post-computed with the new FLUX-version which contains a very effective algorithm to treat supports with gaps and resultant impacts. For treatment of plastic supports, a simple model is added. Pre-computations were not meaningful because of large deviations in the pre-estimated initial gaps. However the computed pressure-field is not influenced very much by these parameters and predicted very well. This was favoured by the isothermal fluid initial conditions. Post-computatic ishow sufficient agreement with respect to computed core barrel motion. The axial motion is described very well. Some problems remain which are due to the model for the upper flange support.

Impacts do not result in greatly enlarged loadings, strains or accelerations for this situation.

\section{Introduction}

Fluid-structure interaction during blowdown of a pressurized water reactor (PWR) has been the subject of extensive experimental and theoretical work $[1,2]$. Large-scale experiments have been performed at the HDR tent-facility [3] (HDR = Heissdampireaktor, superheated steam reactor). We have developed the computer code FLUX [4] for analysis of these experiments and the PWR situation. FLUX uses the shell-model CYLDY3 [5] and for the blowdown-pipe the two-phase non-equilibrium model DRIX-2D [6]. A core model [7] has been also included in FLUX [8] but is not used for the experimental situation, shown in fig. 1.

In the past, both experiments and code models were restricted to an ideally clamped core barrel. But in a real PWR, the core barrel is supported at the upper flange with finite small clearances (typically $10 \mathrm{~mm}$ in diameter and less than $1 \mathrm{~mm}$ vertically). At the lower end, the core barrel's radial motion is restrained by snubbers with initial gaps of the order of $3 \mathrm{~mm}$. It has been speculated that impacts at such supports may induce large forces, accelerations and deformations.

For analysis of such impacts within the three-dimensional fluid-structure motions, the code FLUX had been extended by a very effective algorithm as described in [9]. The code can handle elastic and plastic, rigid and fexible supports at arbitrary positions. The support positions and directions for the HDR-model are shown in fig. 2. This extended method had to be verified experimentally.

For this purpose, a special experiment (case V34) has been performed as the last of the blowdown test series at the HDR facility in April 1982 [10-12]. This paper 


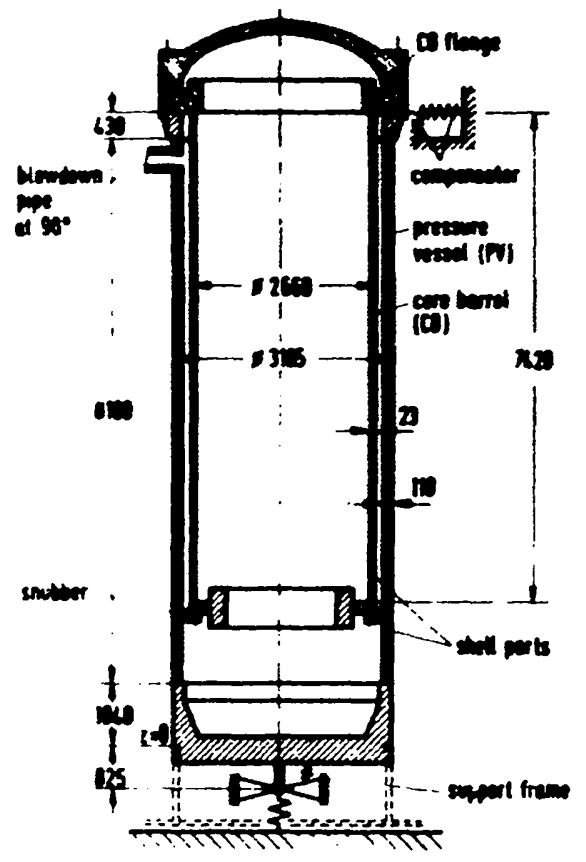

Iig. I. Simplified cross-section of the HDR vessel.
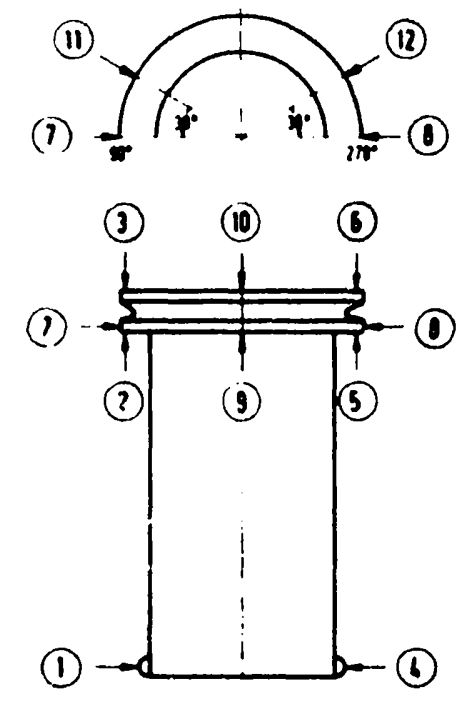

Fig. 2. Support positions and directions in the FLUX midel.

reports about the experiment and results of pre- and post-computations with FL.UX.

\section{The HDR blowdown experiment V34}

The design-goal of experiment V34 was to provide experimental data on motions with impacts between the core-barrel (CB) and the pressure vessel (PV) at snubbers at the lower CB-edge. Design calculations with FLUX showed that the CB displacement at the snubber positions would not exceed $1.6 \mathrm{~mm}$. It was clear that such small displacements would require an unfeasible accuracy in mounting the snubbers in order 10 guarantee suitable initial gaps and impacts. An accuracy of \pm 0.5 to $\pm 1.0 \mathrm{~mm}$ seemed to be feasible but could not be guaranteed in advance.

Therefore, the support of the upper CB-flange was changed such that it had the freedom to move by a small amount horizontally (designed: $1.2 \mathrm{~mm}$ achieved: $0.3 \mathrm{~mm}$ ) and axially (designed: $1 \mathrm{~mm}$, achieved: $2 \mathrm{~mm}$ ). This was cheafly performed by replacing the standard distance ring by one with smaller thickness. The reason for the differences in the designed and actually performed gap values are due to several uncertainties, in particular due to a strong sensitivity of the PV- and CB-diameter to small temperature changes.

At the lower edge, snubbers were installed which were designed to provide initial gaps of $1.5 \mathrm{~mm}$ at $90^{\circ}$ and $1.5 \mathrm{~mm}$ at $270^{\circ}$. (Note, that in the HDR coordinate system, the blowdown pipe is connected to the vessel at $90^{\circ}$ angular direction.) After the experiment, the actual values were estimated to be $1.4 \mathrm{~mm}$ at $90^{\circ}$ and $2.8 \mathrm{~mm}$ at $270^{\circ}$. The latter value is rather uncertain and unexpectedly large. At present, it is assumed that the reason for this large value is due to gaps of the order of $1 \mathrm{~mm}$ between the snubbers and the CB itself. Due to mounting reasons, the snubbers are screwed from below to the $C B$ and this procedure does not exclude such hidden gaps.

The CB was initially located excentrically as far to the $270^{\circ}$ direction as possible. This enlarges the potential to gain kinetic energy on its way to $90^{\circ}$ and enlarges the chance for impacts at the snubbers.

For the fluid, the initial pressure was planned to be 110 bar (achieved: 112 bar), the initial temperature was designed to $240^{\circ} \mathrm{C}$ (achieved: $240 \pm 1^{\circ} \mathrm{C}$ ). Such isothermal conditions were necessary due to possible bypass flows at the loosely supported upper CB-flange. The blowdown is initiated by a membrane break at the end of the blowdown pipe. This mechanism opened the pipe as expected within about $1 \mathrm{~ms}$.

Except for the loose CB support and the isothermal temperature distribution, the experimental parameters are the same as in case of V32 [10], the German standard problem No. 5.

Also the same extensive high-quality measurement system is being used (among others: 39 absolute pressure, 30 difference pre;sure, and 21 displacement transducers). For the present experiment additional trans- 
ducers have been mounted to measure the axial motion of the upper CB-flange and the accelerations near the snubbers and the upper flange at the outer PV wall.

With conservative estimates it had been made sure in advance that the impact loads do not present any danger to the integrity of the HDR test facility. These estimates were based on energy considerations.

\section{Experimental reaults}

\subsection{Fluid dynamics}

The fluid dynamics in case of V34 in the first subcooled blowdown period is very similar to the observations in case of V32 and qualitatively as described earlier for V31.1 $[2,13]$. The pressure in the blowdown pipe drops within $1.3 \mathrm{~ms}$ from its initial value down to 20 bar and then within $16 \mathrm{~ms}$ recovers to the saturation pressure of about 32 bar. In contrast to V32, the pressure inside the vessel, see fig. 3, nowhere drops below the saturation pressure within the first $250 \mathrm{~ms}$ so that one surely has liquid water inside the vessel during this period. The pressure waves, see fig. 4 , show the same remarkable effect of reduced wave-speed due to fluid-structure-interactions as in previous HDR-tests. Also the strong damping effect for the pressure waves in the blowdown-pipe is as observed earlier [13]. The pressure difference at the CB is very similar in V34 and V32 in the first $70 \mathrm{~ms}$, see fig. 3 . This is noteworthy because it shows

- there is no substuntial bypass flow at the loosely supported upper $\mathrm{CB}$-flange.

- the temperature distribution inside the CB does not have significant effect on the pressure loadings.

- the feedback of the changed support conditions on the pressure field is small in comparison to the feedback of shell motions.

- the pressure field shows no clear indications for impacts.

\subsection{Structural dynamics}

Typical displacement signals, which show the relative motion of the CB with respect to the PV are shown in figs. 5 to 7. From these results one obtains the following picture of the $\mathrm{CB}$ motion:

Immediately after blowdown initiation, in the first

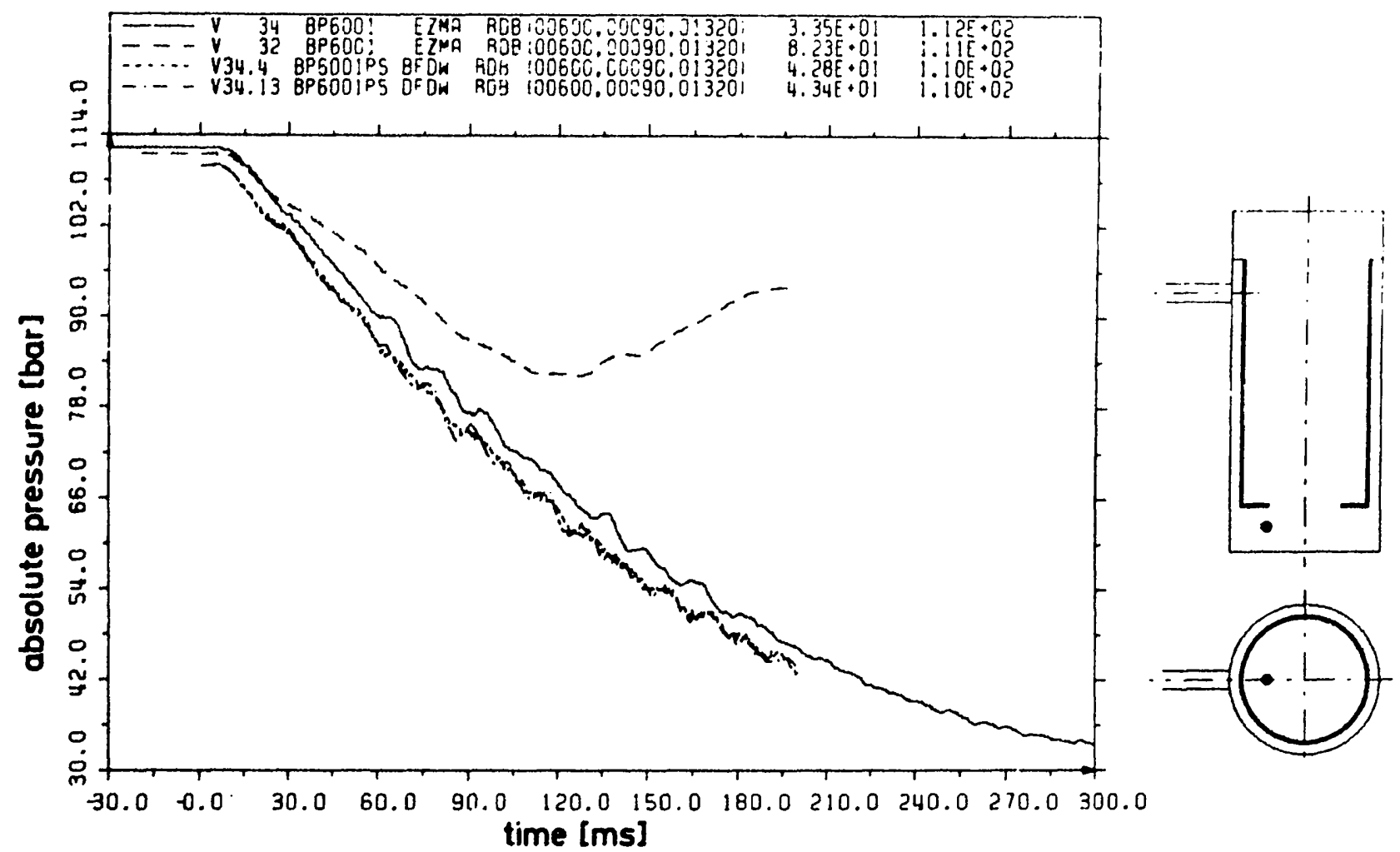

Fig. 3. Absolute pressure in the lower plenum. In all such figures, V32 and V34 (EZM/A) are the experimental, V34.4 (BFDW) are FLUX pre-computations, V34.13 etc. (DFDW) are post-computations. 


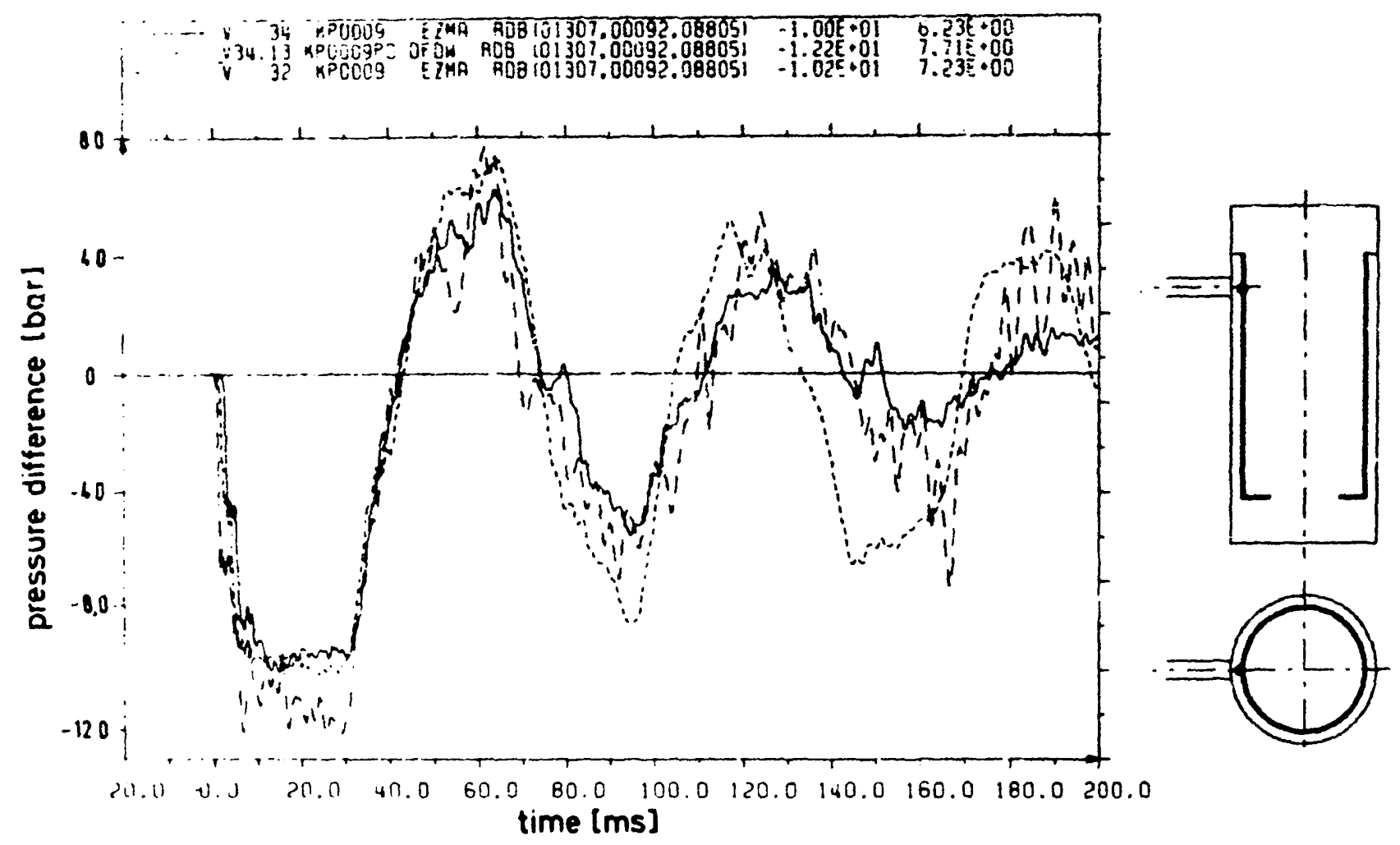

Fig. 4. Pressure difference at the $C B$ near the blowdown nozzle.

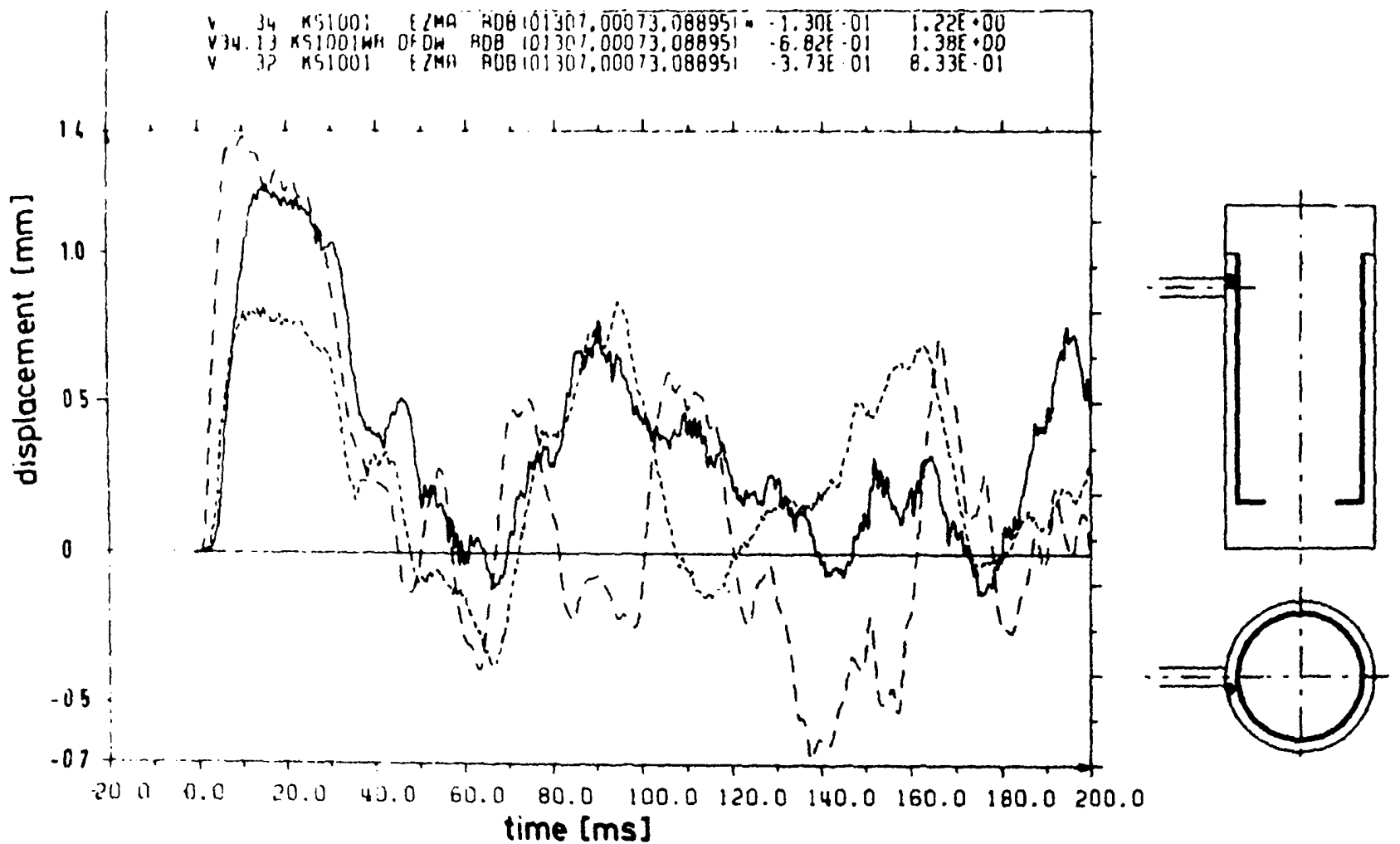

Fig. 5. Radial deflection of the upper CB shell. 
$10 \mathrm{~ms}$, the CB slides horizontally until it hits the upper CB support at $90^{\circ}$. This is concluded from the large difference in V32 and V34 for the radial deflection of the upper CB near $90^{\circ}$, see fig. 5 ; at $270^{\circ}$ the radial deffection is reduced in V34 in comparison to V32. This fact appears in spite of the pressure drop in the downcomer within the first $42 \mathrm{~ms}$ which causes hold-down forces up to five times the CB weight. These downward forces imply large friction forces but, apparently, these are not large enough to prevent the horizontal motion.

Alter $42 \mathrm{~ms}$, the pressure difference changes sign in the upper downcomer domain, see fig. 4. This then causes an upward force which, after $45 \mathrm{~ms}$, is large enough to lift the CB flange upwards, see fig. $6.10 \mathrm{~ms}$ later, the nange hits the constraint at the upper lid. Thereafter, the CB falls down, agnin in strong correlation with the pressure difference, and later a second jump appears. The CB flange remains virtually horizontal throughout the axial motions.

After $230 \mathrm{~ms}$ the flange seems to become caught from the sideward support. This is possible because the initial horizontal gap is small ( $\approx 0.3 \mathrm{~mm}$ ) and a general pressure reduction by 50 bar in the vessel causes a 0.44 $\mathrm{mm}$ shrinking of the PV flange. The remaining $100 \mathrm{~Hz}$ oscillation in fig. 6 has been identified as being eigenoccillations of the device to which the transducers are mounted.

The lower edge of the CB with its $90^{\circ}$-snubbers, see fig. 7, impacts the P'V first at a time around $33 \mathrm{~ms}$ after having closed the initial gap of $1.4 \mathrm{~mm}$. Such an impact is also indicated by $0.2 \mathrm{~mm}$ deep plastic marks from the snubbers in the inside PV wall which have been found after the experiment. The CB and PY remain in contact up to about time 90 ms.

Thereafter, the CB swings back and impacts at $270^{\circ}$ angle at a time between 130 and $145 \mathrm{~ms}$. It remains in contact there for a time period which is estimated to take between 50 and $80 \mathrm{~ms}$. Also at $270^{\circ}$. plastic marks but of smaller deepness $(=0.1 \mathrm{~mm})$ have been observed afterwards. The total displacement $(1.4+2.8 \mathrm{~mm})$ be. tween the two impacts is larger than expected. Possible: reasons are uninterided gaps between the snubbers and the $\mathrm{CB}$ as explained in section 2.

The general motion of the $C B$ is essentially symmetric with respect to the $90^{\circ}$ direction.

The PV motion is measured from the outside with $y$ displacement transducers. The vessel is mounted to a lower support frame. The measurements, see e.g. fig. 8 ,

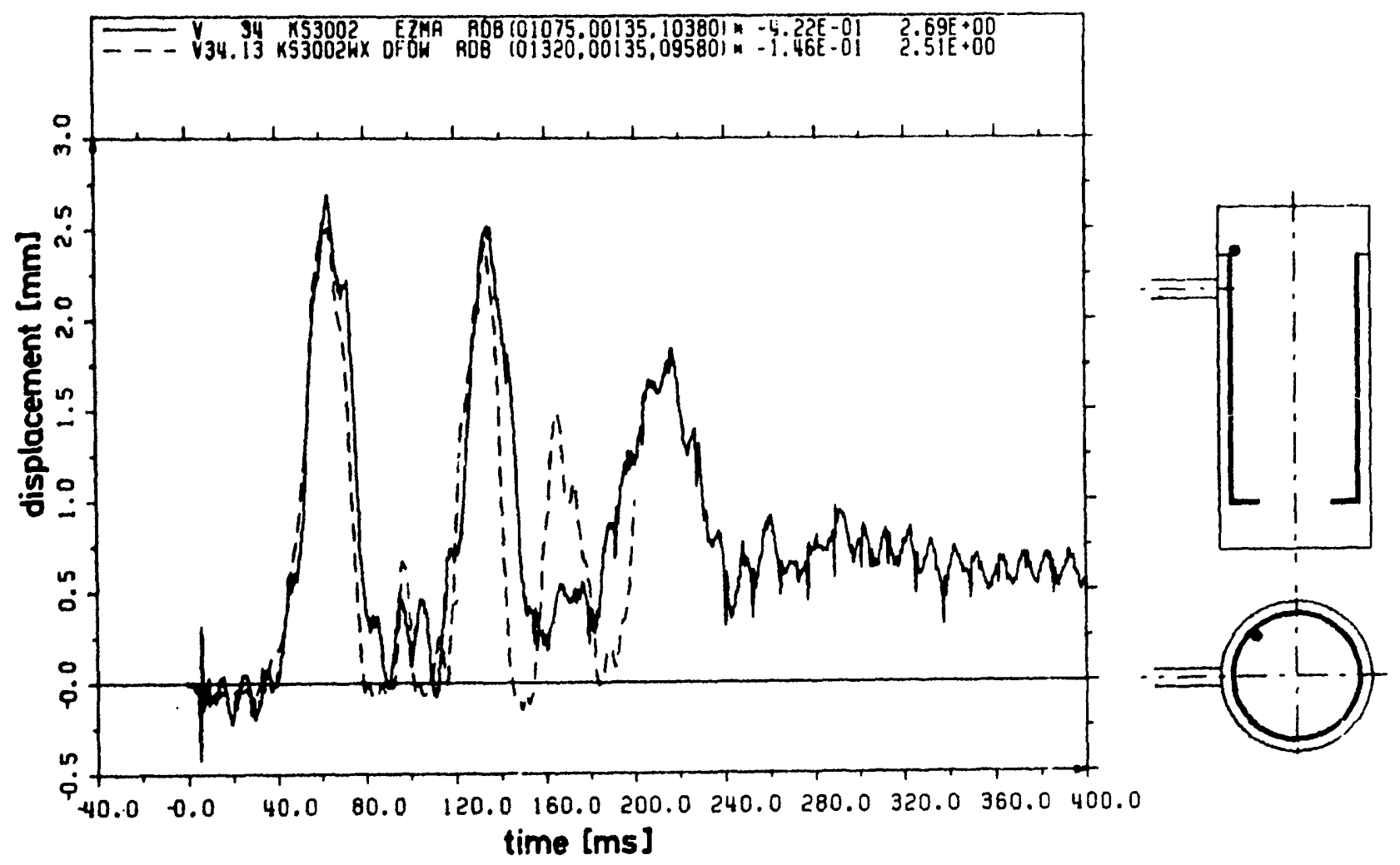

Fig. 6. Axial displecement of the upper CB flange. 


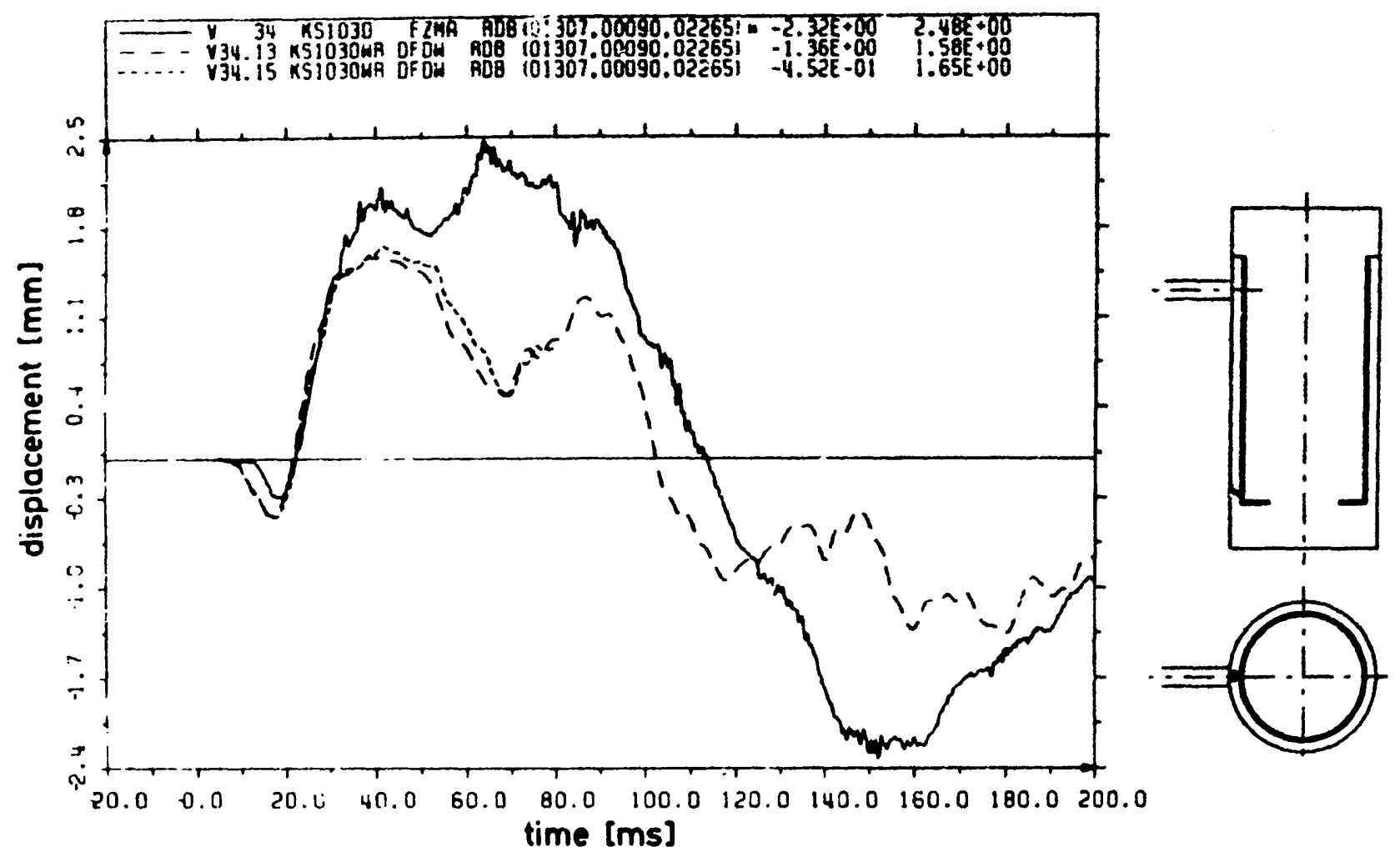

Fig. 7. Ratial deflection near the $90^{\circ}$-snubber.

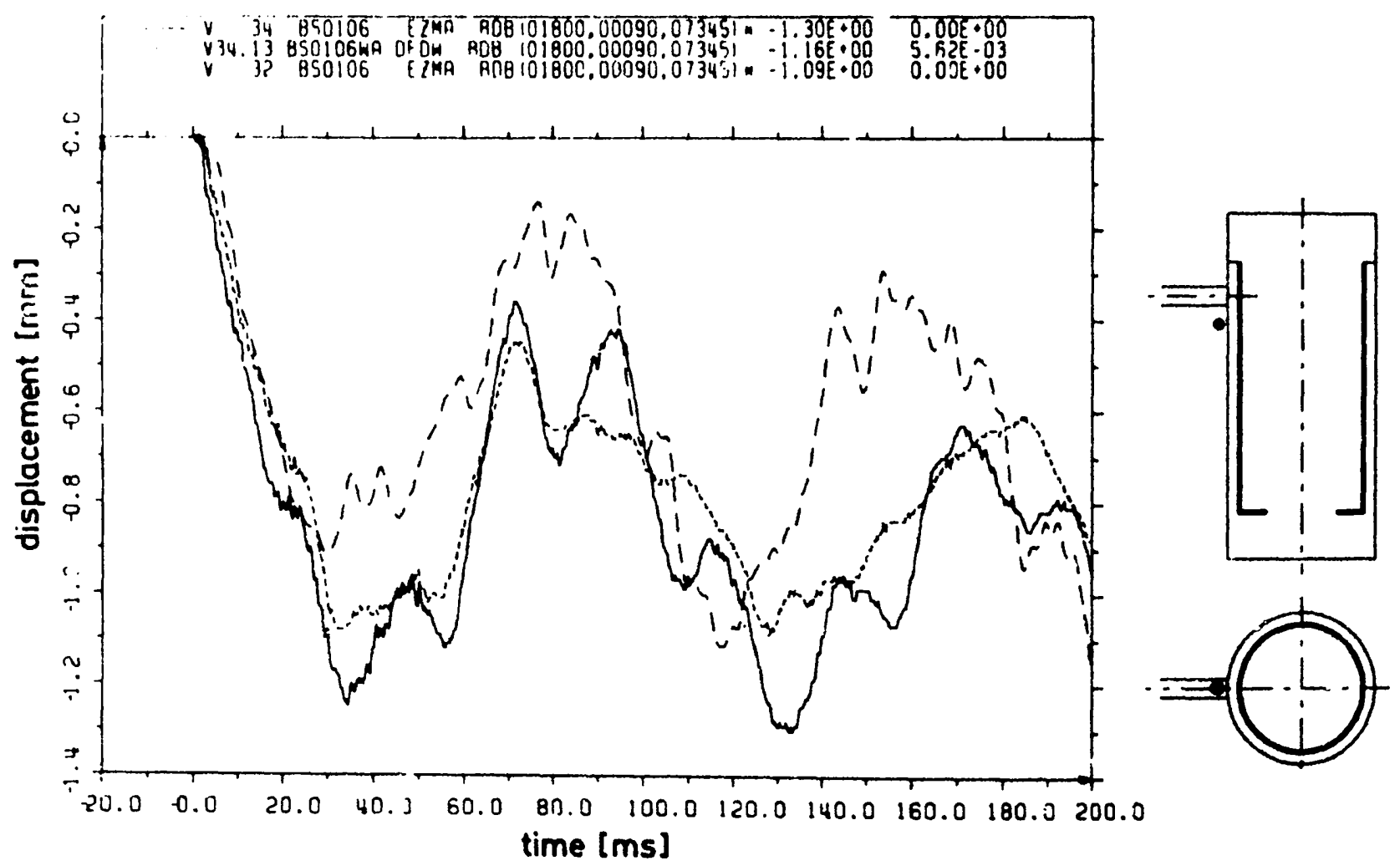

Fig. 8. Sideward deflection of the PV. 


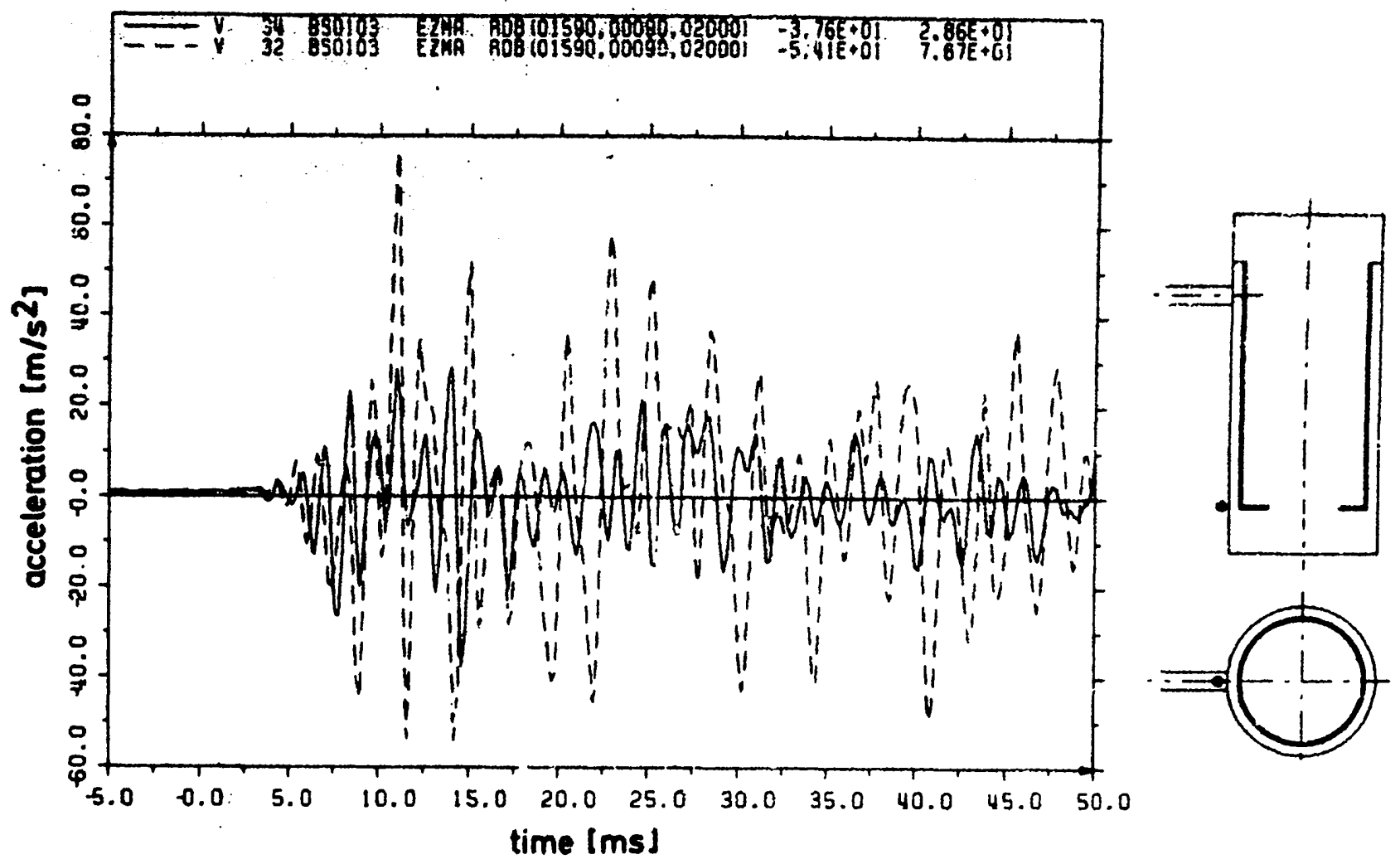

Fig. 9. Acceleration at the outside PV near the $90^{\circ}$-snubber.

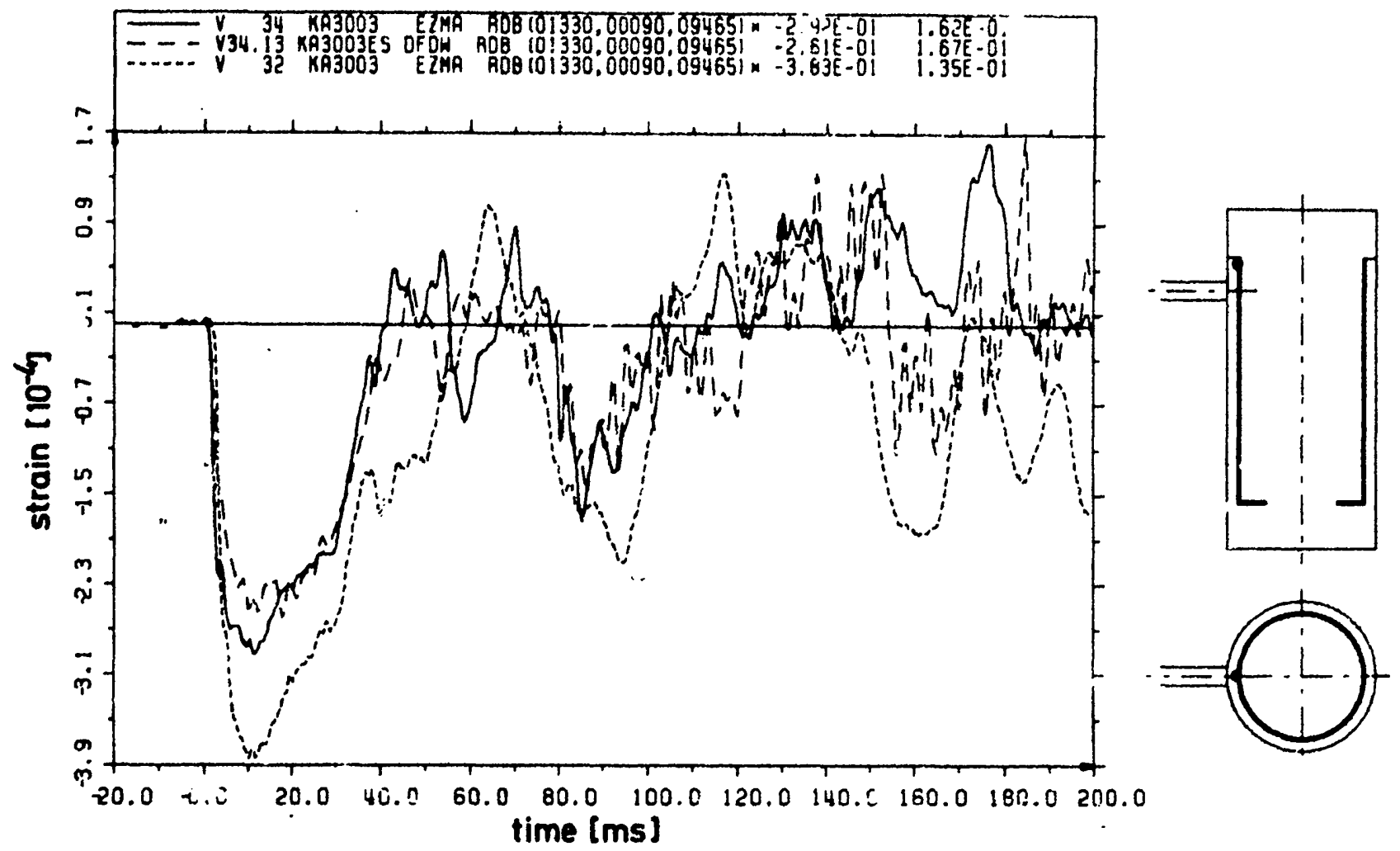

Fig. 10. Axial struin at the outside $\mathrm{Cb}$ shell near the blowdown nozale. 
show that the vessel mainly oscillates in the beam mode with an amplitude of $1.3 \mathrm{~mm}$ at the upper flange. In addition some shell modes of the vessel are indicated with amplitudes of $0.1 \mathrm{~mm}$. In comparison to $V 32$ the sidewards initial acceleration caused by the reaction force of the outflowing fluic are 20\% larger. This is probably a consequence of the reduced effective inertia of the PV with its loosely cunnected CB.

Surprisingly, none of the accelerometers, neither at the CB nor at the outside PV wall in the vicinity of the upper flange and the snubbers show clear indications of impacts. see fig. 9. Thus the impact feces are small in comparison to other forces.

The strain values measured at the CB for $\mathrm{V} 34$ are of the same amplitude as or smaller than in experiment v32. The impacts do not cause large additional strains. An example is shown in fig. 10.

\section{The computer code FLUX}

The code FLUX [4.13.14] has been used in the version FLUX4 which includes fluid-structure interactions with the CB and the PV and the algorithm for treating impacts described in [9].

The two-phase flow in the blowdown pipe is precomputed with DRIX-2D [6] (actually, the computation is identical to the V 32 version (14]). The resultant pressure. $105 \mathrm{~mm}$ downstream the downcomer in the pipe is then used as boundary value for the subsequent FLUX4 run. This is the so called weak coupling as explained in [13] which performs totally satisfactorily.

The dynamic properties of the CB and the PV are described by rigid hody parts and shell eigensolutions constructed with CYLDY3 [5,14] as indicated in fig. 1. The upper and lower end rings of the $C B$ are treated as elastic rings. The upper PV flange is modelled as being rigid. Note that the CB has three zero eigenfrequencies according to its rigid body degrees of freedom (axial, tilting, horizontal motion).

The fluid motion in the vessel is modelled as a compressible potential now with constant speed of sound $(a=1200 \mathrm{~m} / \mathrm{s})$ and nominal density $\left(\rho_{0}=816\right.$ $\left.\mathrm{kg} / \mathrm{m}^{3}\right)$. At the nozzle from the downcomer into the blowdown pipe, a turbulent friction pressure drop $\left\lfloor\zeta \rho_{0} u|u|\right.$ is assumed with $\zeta=0.4$. This value is essential for obtaining the correct mass flow rate. The fluid-structure interaction is treated implicitly for small wall deflections as described earlier [4,13].

In comparison to [9], the code has been extended by a simple technique to treat an ideal elastic/plastic behaviour of supports: As additional input parameter a "plasticity force" $\boldsymbol{K}_{\mathrm{p}}$ is introduced for each support. If the input value $K_{p}$ is zero then the support is treated as purely elastic (which actually means $K_{p}-\infty$ ). If $K_{p}>0$ in the input, then during the integration after each time step, the computed support force $k$ (which is non-positive) is compared with $K_{p}$. If $|k|>K_{p}$, then the support is treated as ideally plastic, i.c. we enlarge the initial gap $s$ and reset the force $k$ according to $s:=s+\left(|k|-K_{p}\right) F$, $k:=-K_{p}$. Here, $F$ is the inpul value defining the elastic support fexibility. The force-displacement diagram for such supports is shown in the appendix. The total sum of plastic deformations are recorded and output for each support. This procedure is totally consistent with the algorithm given in [9].

For a one-degree-of-freedom model-problem, see appendix, one can analyse the resultant energy loss $\Delta E$ during impact due to plastic work. One finds that the model-problem is dependent on only one characteristic number $N \equiv(M / F)^{1 / v_{0}} / K_{p}$, where $M$ is the mass of the impacting structure and $v_{0}$ its impact velocity.

The computations are carried through for two discretisation parameters, $\mathrm{M} 1$ (coarse) and M2 (fine). The two grids are distinguished only by the number of mesh cells on half the circumference (symmetry is taken into account) which are 12 for $M 1$ and 16 for $M 2$, the cutoff eigenfrequency of the structural eigenfrequencies are $637 \mathrm{~Hz}$ for $\mathrm{Ml}$ and $1500 \mathrm{~Hz}$ for M2, and the time step is of size $0.5 \mathrm{~ms}$ in $\mathrm{Ml}$ and $0.2 \mathrm{~ms}$ in $\mathrm{M} 2$. The finite difference grid in the r-z-planes is indicaled in fig. 11

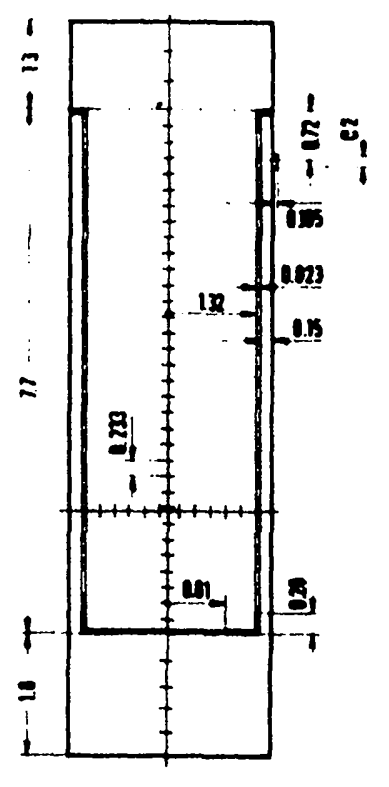

Fig. 11. The model for the nuid domain and grid used in FLUX. Grids M1 and M2 do not differ in this plane but differ mainly with respect to the azimuthal spacings. 
Table 1

Support parameters*

Case V34.4 (pre-computatior urith supports no. 1 to 8)

\begin{tabular}{llllllllllllll} 
No. & 1 & 2 & 3 & 4 & 5 & 6 & 7 & 8 & 9 & 10 & 11 & 12 & - \\
\hline$s$ & 1.5 & 0 & 1.0 & 1.5 & 0 & 1.0 & 1.2 & 0 & - & - & - & - \\
$F$ & 1.0 & 1.0 & 2.0 & 1.0 & 1.0 & 2.0 & 0 & 0 & - & - & - & - \\
$K_{\mathrm{p}}$ & 0 & 0 & 0 & 0 & 0 & 0 & 0 & 0 & - & - & - & - \\
\hline
\end{tabular}

Case V34.13/15 (post-computation with supports no. 1 to 12)

\begin{tabular}{llllllllllllll} 
No. & 1 & 2 & 3 & 4 & 5 & 6 & 7 & 8 & 9 & 10 & 11 & 12 & \\
\hline$s$ & 1.4 & 0 & 2.0 & 2.8 & 0 & 2.0 & 0.3 & 0 & 0 & 2.0 & 0.28 & 0.02 \\
$F$ & 1.0 & 0.2 & 4.0 & 1.0 & 0.2 & 4.0 & 0 & 0 & 0.4 & 4.0 & 0 & 0 & 0 \\
$K_{p}$ & 0.53 & 0 & 0 & 0.53 & 0 & 0 & 0 & 0 & 0 & 0 & 0 & 0 \\
\hline
\end{tabular}

- $s=$ initial gap $[\mathrm{mm}], \quad F=$ support flexibility $\left[10^{-10} \mathrm{~m} / \mathrm{N}\right], \quad K_{\mathrm{p}}=$ plasticity force $[\mathrm{MN}]$; for support numbers, set fig. 2.

and is the same for $M 1$ and $M 2$. The number of fluid mesh cells $n_{F}$ and structural modes $n_{S}$ are $\left(n_{F}, n_{S}\right)=$ (2839, 321) for $\mathrm{M} 1$, and $=(3699,861)$ for $M 2$. The computing time on an IBM 3033 is $1 \mathrm{~h}$ for M1, and $6 \mathrm{~h}$ for M2 for integrations over $200 \mathrm{~ms}$.

The support parameters are specified in table 1. The values of $K_{\mathrm{p}}$ and $F$ to be taken can be roughly estimated from the plastic force capacity and flexibility of the actual snubbers according to their geometrical dimensions and material values. A somewhat larger value should be assigned for $F$ in order to account for the Nexibility of the immediate surrounding of the snubbers. The values used in the post computations V34.13/15 are best estimates.

\section{Comparison between measured and computed values}

\subsection{Precomputation V34.4}

The code FLUX has been used for pre- and post-lest analysis. Case V34.4 denotes the pre-computed result. The pre-test-analysis gave generally very good agrcement with respect to fluid dynamic quantities, see e.g. figs. 3, 4, and 12 .

In the time period 10 to $40 \mathrm{~ms}$, the pressure difference at the CB is overestimated by up to 15\%, see fig. 4; later the errors are smaller. This is caused by a too large pressure drop computed by the two-phase model in the blowdown-pipe. The overall agreement in the fluid data is very good, however. It is better than in case of V32 where some small additional errors arise due to early two-phase effects inside the vessel.

However, the structural results, did not agree because the pre-estimated initial gap values differed considerably from the actua lalues as repor:ed in section 2 so that post-computatioiss have been $n$ : $c$. ary. On the other hand, the good agreement of the fluid data inspite of the structural deviations, shows again that the feedback of the support parameters and the impacts on the fluid is small in comparison to the ficedhack of the shell motions.

\subsection{Past-computations V34.13 and V34.15}

Several post-computations have been made in which parameter studies with respect to the optimal supportparameters have been conducted. In these studies the following input parameters have been varied: initial gaps, support flexibilities, plasticity forces, number of support positions (1-8 or 1-12 of fig. 2), and the stiffness of the upper CB flange. We have not changed any fluid model parameter and even left the initial pressure at 110 bar in spite of the measured value of 112 bar because this has an easily interpretable effect and adjustment would require a new DRIX run.

As "best" post-computation we finally classified the computation cases V34.13 and V34.15 which differ only in the discretisation (M1 for V34.13/M2 for V34.15) and integration times $(200 \mathrm{~ms} / 80 \mathrm{~ms})$. In general the effect of the discretisation has been found to be negligible, see fig. 7, e.g; Ml gives sufficient accuracy.

For the fluid pressure-field, the post-computation, see fig. 3 e.g., gives only a little improvement of the 


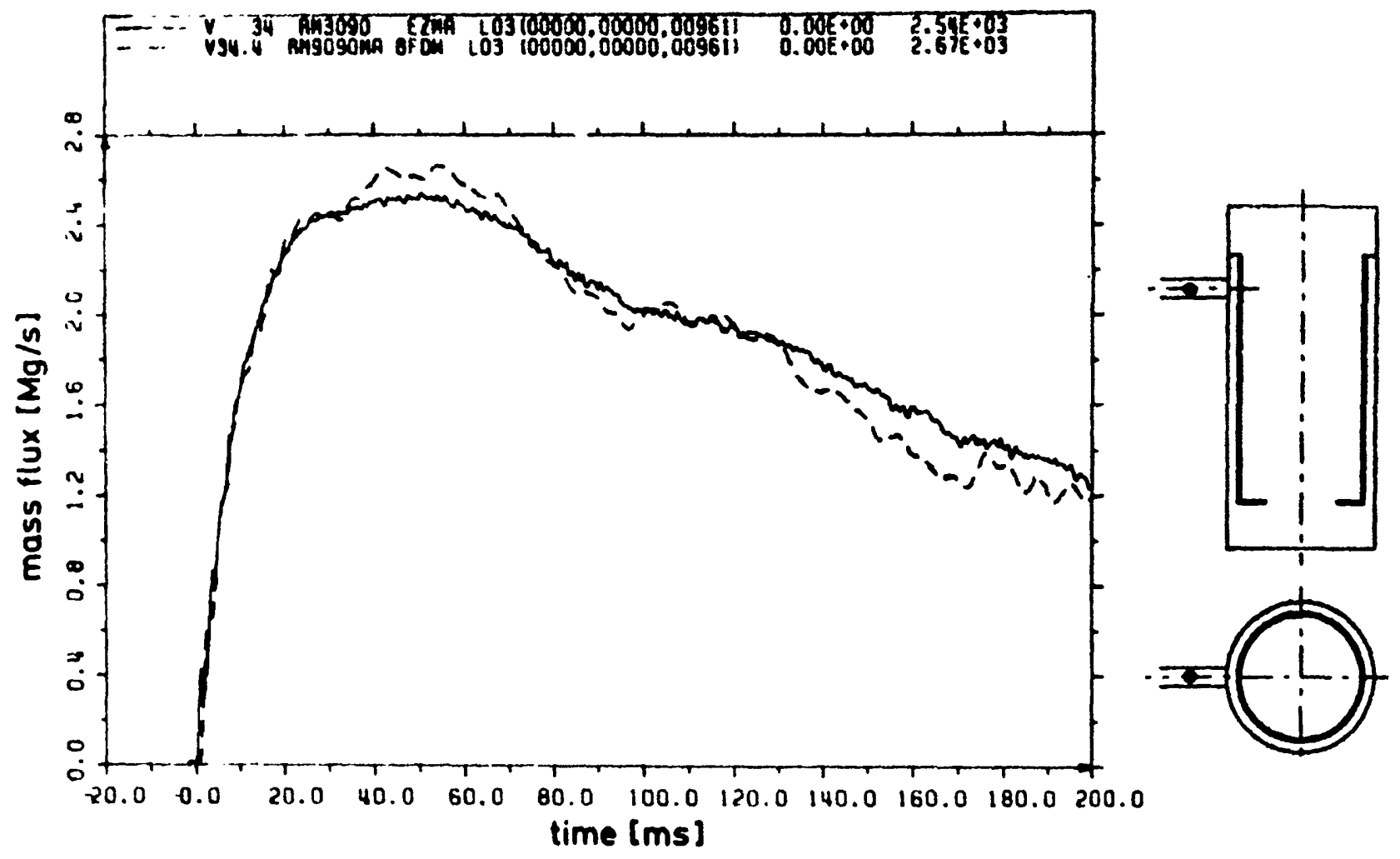

Fig. 12. Mass fi.sx measured and computed at the FLUX4-model exit.

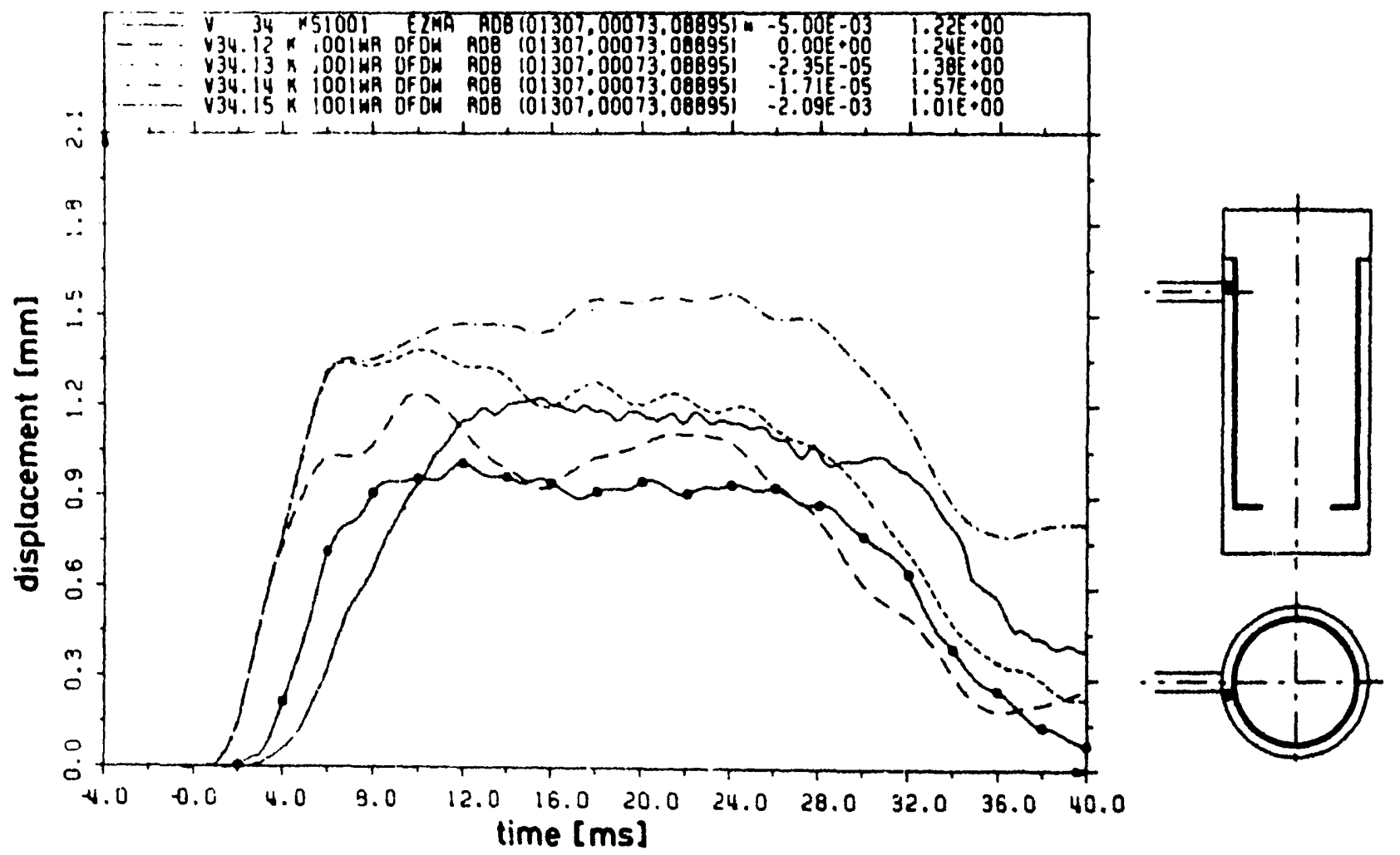

Fig. 13. Radial deflection of the upper CB shell. V34.12: rigid upper CB-flange. V34.13: reference case with elastic ring and 12 supports, V34.14: only 8 supports, V34.15: as .13 but fine grid M2. 


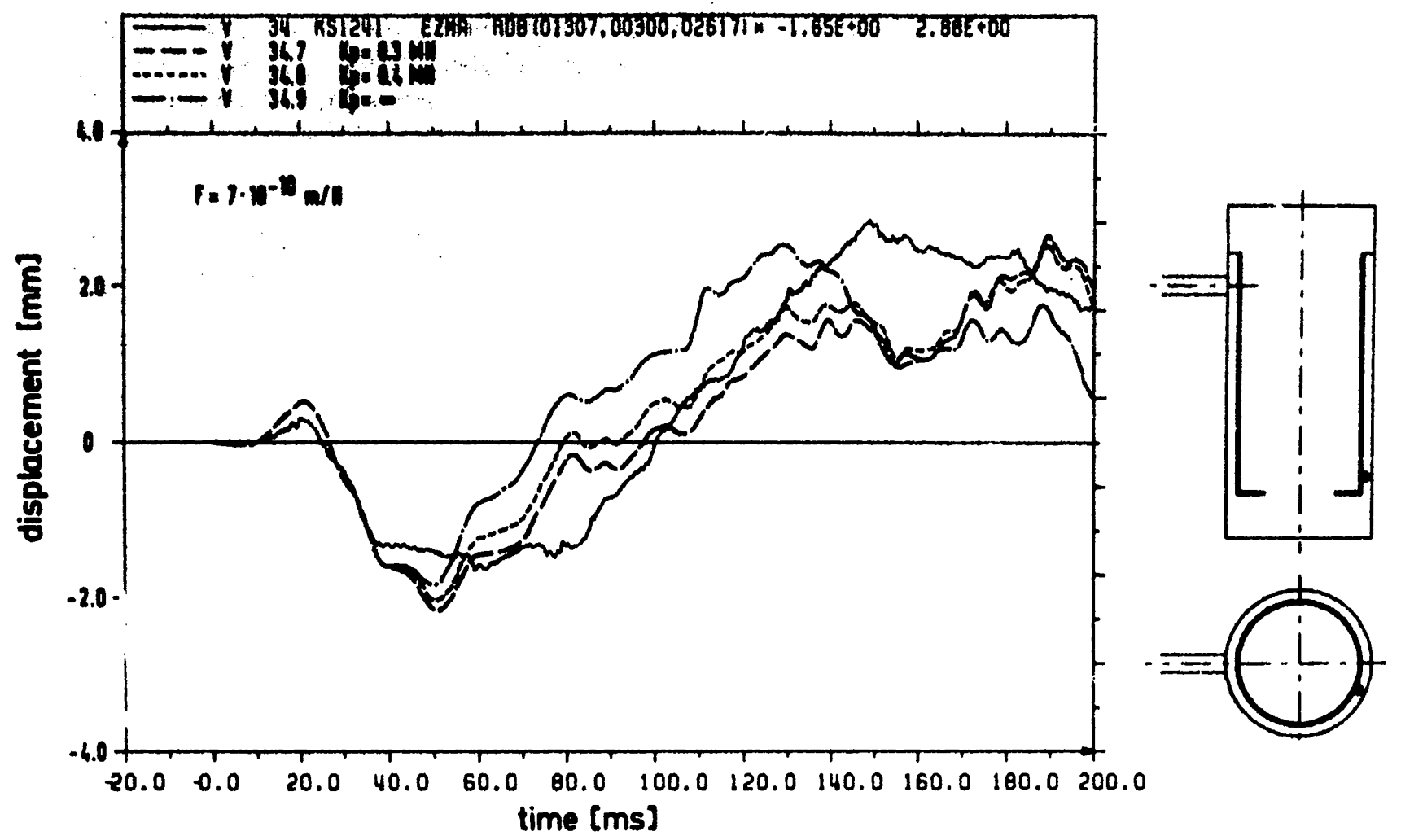

Fig. 14. Effect of plasticity limit $K_{p}$ on deflection near the $270^{\circ}$-snubber.

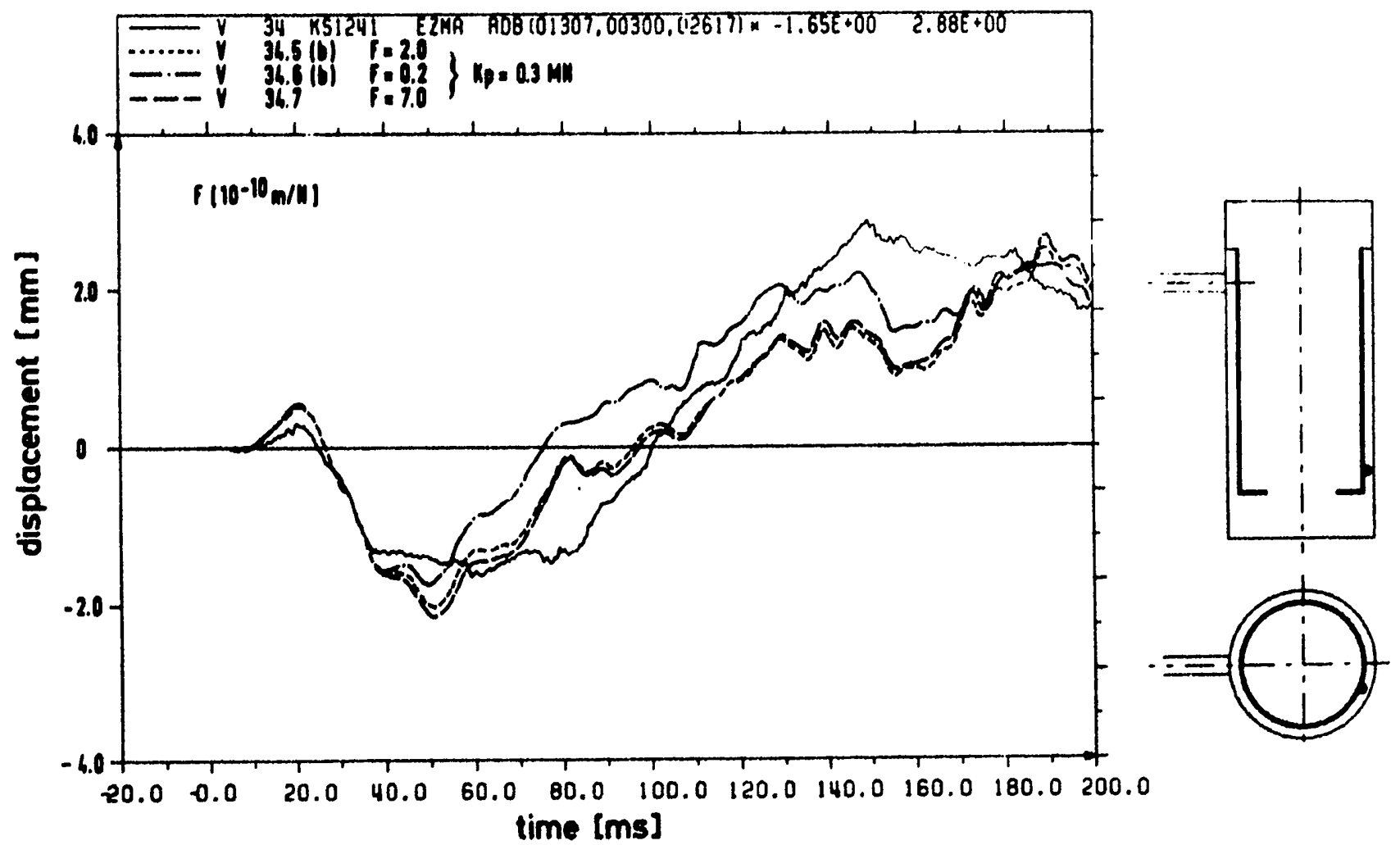

Fig. 15. Effect of the flexibility $F$ with plastic snubbers on the deflection near the $270^{\circ}$-snubber. 
already very good precomputation. The CB motion is n. $3 \mathrm{~W}$ in better agreement with the measured data, although generally not as good as for case V32.

The axial CB motion, see fig. 5, shows that the computation iclealy reproduced the motion of the upper flange with its impacts. This agreement is very insensitive to all model parameters varied and was cubtained immediately after adjusting the initial gaps. This result clearly demonitrates the validity of the algorithm for treating impacts in FLUX.

The radial CB motion is not reproduced to the same quality. The shell deflection (and axial strain) in the upper CB part. fig. 5 . is the most sensitive quantity with respect to discretisation fineness. Interestingly, the finer mesh gives smaller defiections. Further these results are very sensitive to support parameters and upper flange stiffness. see fig. 13. As the upper CB flange is not clamped. its flexibility causes large additional defleclions.

Near the snubhers. the computed deflections show still considerable differences with respect to the measurements. At first it was believed that these discrepancies are due to effects of plastic deformations at the snubbers. Intermediate parameter studies, with different flexibilities and plasticity forces $K_{p}$ (see figs. 14 and 15), showed that this effect cannot be responsible for the general deviations, although the computations explained the small plastic deformations at the inside PV wall (the computed plastic deformation is $0.15 \mathrm{~mm}$ for case V 34.13 at $90^{\circ}$, and zero at $270^{\circ}$ ).

The main reason for the remaining deviations comes apparently from the model for the upper CB flange and its support. This has to be concluded, e.g., from fig. 16 which shows large effects of the parameters in this part. As a consequence it is very likely that even small one-sided friction forces which try to resist the axial motion of the upper CB flange will cause large effects on the motion at the lower CB edge. Such effects are certainly very difficult to describe theoretically. Further such effects are solely relevant for the HDR but not for a PWR with much different construction and larger horizontal gaps. Therefore the parameter study has been finished at this stage.

Strain values, see fig. 10, are well reproduced by FLUX. The computed maximum equivalent stress is 81 $\mathrm{MPa}$ for the membrane part and $118 \mathrm{MPa}$ for the total

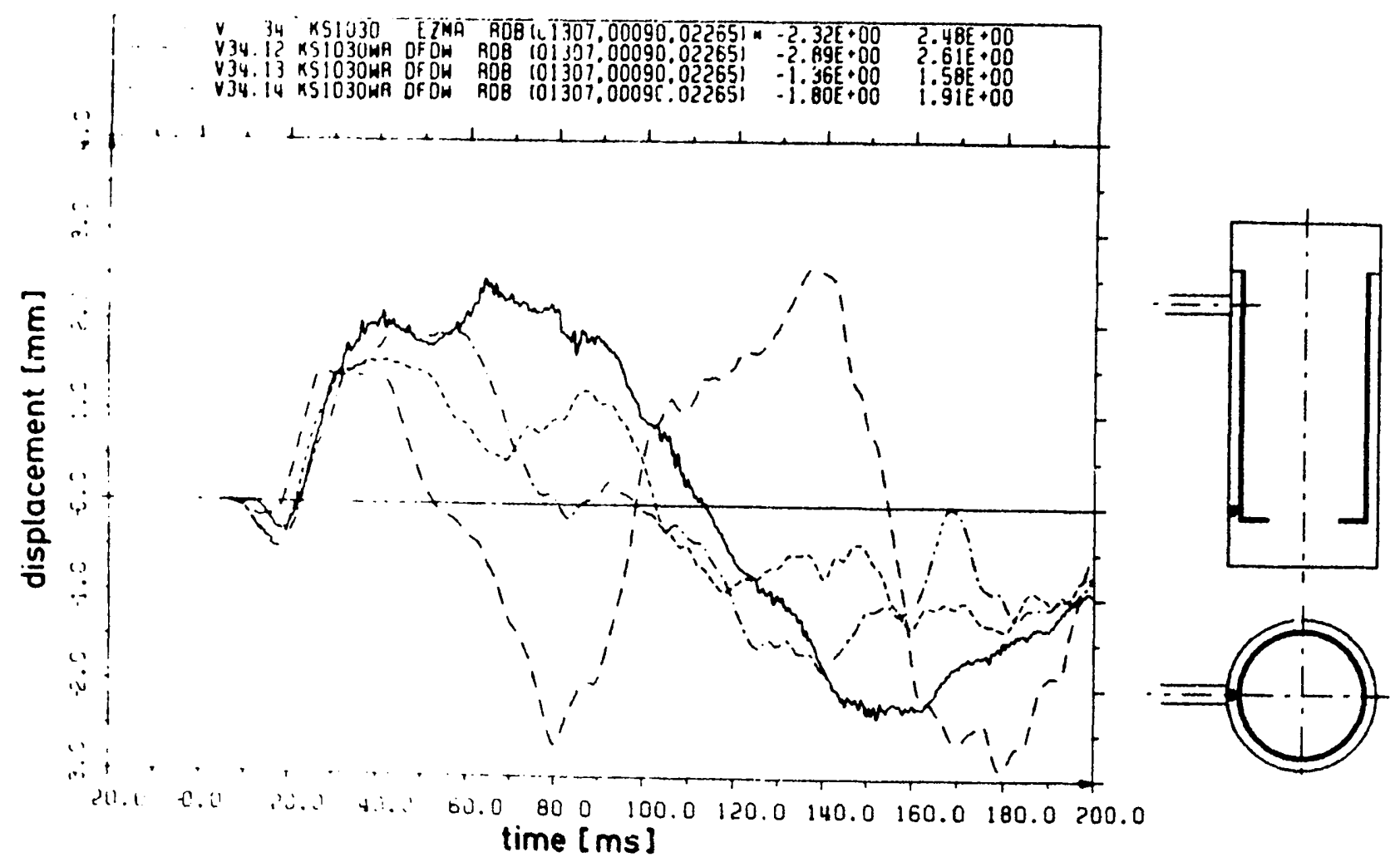

Fig. 16. Radial deflection near the $90^{\circ}$-snubber. V34.12: rigid upper CB-flange. V34.13: reference case with elastic ring and 12 supports, V34.14: only 8 supports. 
stresses including bending. These values are well below the elastic limits. Further, they are of the same order as computed for the case V32 mentioned in section 2. The same is true with respect to accelerations. In fact, FLUX predicted that the impacts have no large effects in terms of acceleration peaks.

\section{Conchuions}

In the HDR blowdown experiment V34, for the first time, fluid-structure interaction with impacts between the core-barrel (CB) and pressure-vessel (PV) has been the primary aspect of large scale experimental investigation and successfully measured. The initial gaps at the different supports have been identified to an accuracy of $\pm 0.2 \mathrm{~mm}$. With these data, code validation is possible. Pre-computations were not meaningful because of large deviations from pre-estimated initial gap values.

Post-computations have been performed with FLUX. In this experiment, FLUX matches the pressure values very good. For the isothermal temperature conditions the FLUX fluid model is particularly suitable whereas in case V32 some larger, but still small errors arise because of early two-phase effects. Even the pre-computations did show excellent agreement with the measured pressure values. This indicates that the structure-fluid feedback effect of the support details and the impacts is small in comparison to the effects of shell dynamics.

The structural dynamics has been fairly well matched by the FLUX post-computations. The agreement is not as good as for V32 but this was to be expected for the more complicated boundary conditions. The axial motion of the upper CB flange, however, and its impacts are reproduced convincingly well. Some small effects of plasticity at the snubbers have been demonstrated. The main cause for the remaining differences in the horizontal CB motion are to be attributed to model uncertainties in the upper CB flange, its stiffness, its support, and possible friction forces resisting its motion. These effects are peculiar to the HDR situation because in a PWR the flange differs in design and has larger horizontal gaps. In any case such details are not essential for assessing reactor safety. It has been shown that FLUX gives a valid model for such motions with impacts.

The forces, strains, and accelerations induced by impacts are small. This has been shown both in the experiment and the computation. It remains to be shown by proper applications of FLUX with adjusted input parameters including the core model $[7,8]$ that this conclusion can be quantitatively transferred to a PWR. Then one can be sure that such impacts provide no concern with respect to the integrity of the vessel internal structures due to blowdown loads.

Appendix: Modet-problem for analyats of a plastic support

We consider the case of a single mass of size $M$ touching the idealized elastic-plastic support as sketched in fig. 17. The support has an elastic stiffness $S$ and maximum force capacity $\boldsymbol{K}_{\mathrm{p}}$. The initial mass velocity is $v_{0}$. The displacement of the support is denoted by $y$. The force-displacement diagram is shown in fig. 18 and the expected time-function $y(t)$ is as given in fig. 19.

The problem is characterized by the four parameters $K, M, S, v_{0}$. From the principal of Buckingham it follows that there is exactly one dimensionless characteristic number. We define this number as the ratio of inertia force $M v_{0} \omega=M^{1 / 2} v_{0} S^{1 / 2}$ to the force capacity $\boldsymbol{K}_{\mathbf{p}}$ :

$N \equiv M^{1 / 2} S^{1 / 2} v_{0} / K_{\mathrm{p}}=M v_{0} \omega / K_{\mathrm{p}}$.

Here the characteristic frequency

$\omega \equiv(S / M)^{1 / 2}$

arises.

We now make all variables dimensionless with the length-scale $L$, time-scale $T$, and force $K$.

$L=v_{0} / \omega, \quad T=1 / \omega, \quad K=M v_{0} \omega$,

and consider $y, t$ as dimensionless displacements and times. Then, one has the following relations:

(Al) $0 \leq t \leq t_{n}$, elastic compression:

$y+y=0, \quad y(0)=0, \quad \dot{y}(0)=1$,

$\rightarrow y=\sin t$.

$y=y_{\mathrm{s}}$ for $y_{\mathrm{s}}=\sin t_{\mathrm{s}}, \quad y_{\mathrm{s}}=1 / N$,

$\rightarrow t_{\mathrm{s}}=\arcsin (1 / N)$ for $N>1$,

if $N \leq 1$, then the elastic range will not be left and the total contact time is

$\Delta t=\pi$, i.e. $\Delta \hat{t}=\pi / \omega$ in dimensional terms.

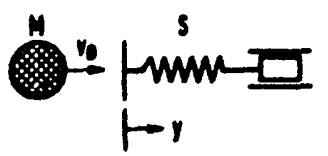

Fig. 17. Model-problem. 


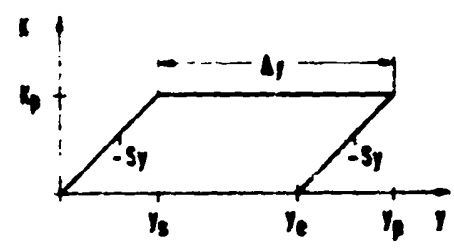

Fig. 18. Force $K$ versus displacement for the ideal plastic support.

(A.2) $t, \leq t \leq t_{p}$, plastic compression:

$\ddot{y}+1 / N=0, \quad y\left(t_{s}\right)=1 / N, \quad \dot{y}\left(t_{s}\right)=\cos t_{s}$,

$\rightarrow y=1 / N+\left(\cos t_{3}\right)\left(t-t_{3}\right)-\frac{1}{2}\left(t-t_{3}\right)^{2} / N$.

The end-time $t_{p}$ of the plastic range is reached when $i\left(t_{p}\right)=0$. It follows

$t_{n}-t_{1}=N \cos t_{1}$.

$y_{p}=1 / N+!_{2} N \cos ^{2} t_{3}$.

Thus the total plastic defornation is

$J v=y_{n}-v_{4}=! N \cos ^{2} t_{4}$.

$(A 3) t_{p} \leq t \leq t_{e}$ elastic expansion:

$v+\left(v-s_{i, 1}=0, \quad y\left(t_{p}\right)=\therefore p, \quad \dot{v}\left(t_{p}\right)=0\right.$.

$v=v \cos \left(1-t_{n}\right)+\Delta y$.

Thic mass leaves the spring when $y\left(t_{c}\right)=\Delta y$.

$t_{c}-t_{p}=\pi / 2$.

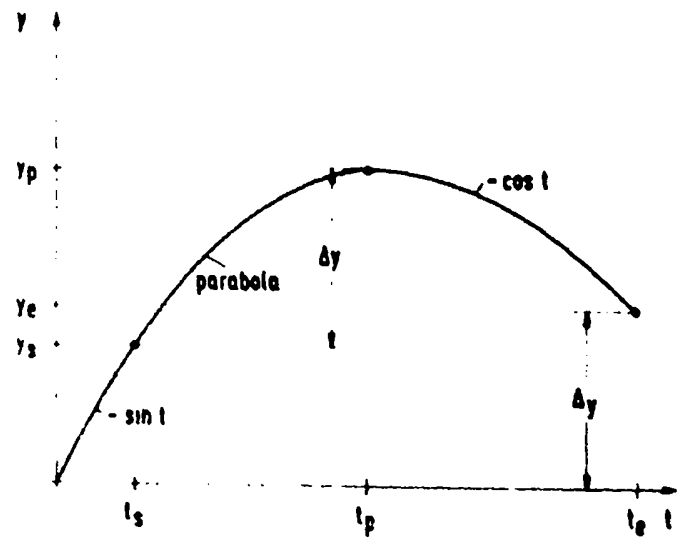

Fig. 14. Displacement $v$ at the support versus time $t$.
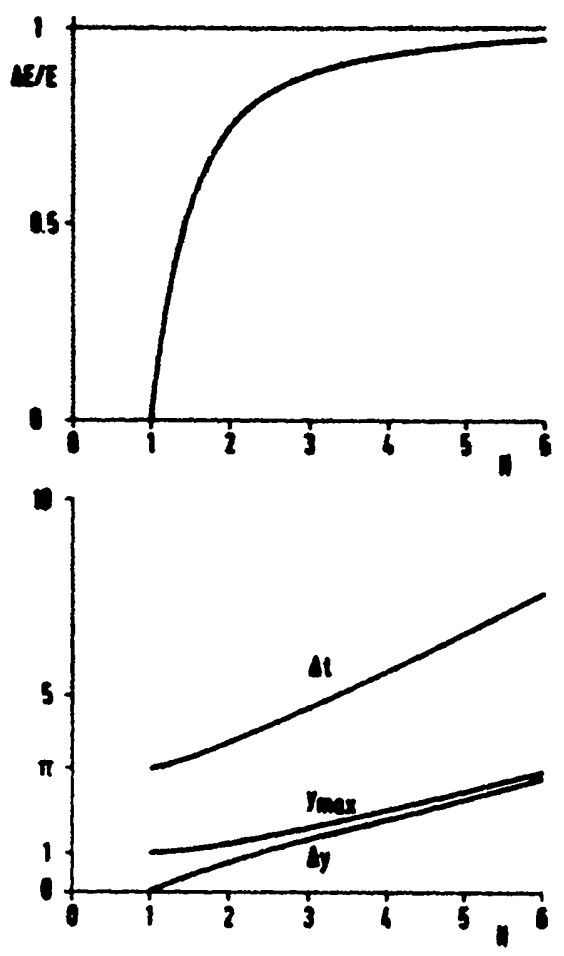

Fig. 20. Energy loss $\Delta E / E$, contact time $\Delta$, maximum dier placement $y_{\max }$ and plastic deformation $\Delta y$ versus the characteristic number $N$.

From these results we can evaluate the energy loss $\Delta E$ :

$$
\begin{aligned}
\Delta E / E & -\left[y(0)^{2}-y\left(t_{e}\right)^{2}\right] / \hat{y}(0)^{2} \\
& =1-(1 / N)^{2} .
\end{aligned}
$$

The total contact time for $N \geq 1$ is

$\Delta t=\left(t_{e}-t_{p}\right)+\left(t_{p}-t_{s}\right)+t_{s}$.

$\Delta t=\pi / 2+N \cos t_{8}+t_{\mathrm{a}}, \quad t_{\mathrm{s}}=\arcsin 1 / N$.

Other characteristic results are the plastic deformation $\Delta y=\frac{1}{2} N \cos ^{2} t_{3}$ and maximum deflection

$y_{\max }=y_{p}=1 / N+\Delta y$.

These results are plotted versus $\boldsymbol{N}$ in fig. 20.

\section{Acknowledsement}

Several colleagues of the Institut fur Reaktorentwicklung and the Project HDR have contributed to this 
work. The author is particularly grateful to M. Oeiss, F. Katz, H. Knqppel, R. Kries. A. Ludwig and E.G. Schlechtendahl, and the PHDR team who performed the experiment and data processing.

\section{References}

[I] T. Belyechko and U. Schumann, Fluid-structure interactions in light water reactor systems, Nud. Engrg. Des. 60 (1980) 173-195.

(2) L. Woll, Experimental res'lts of coupled fluid-structure interactions during blowdown of the HDR-vessel and comparisons with pre- and post-test predictions. Nucl. Engre. Des. 70 (1982) 269-308.

[3] R. Krieg, E.O. Schlechtendahl and K.-H. Scholl, Design of the HDR experimental program on blowdown loading and dynamic response of PWR-vesel internals. Nucl. Engrg. Des. 43 (1977) 419-435.

[4] U. Schumann, Fast elliptic solvers and three-dimensional fluid-structure interactions in a pressurized water reactor, J. Comp. Phys. 36 (1980) 93-127.

[5] A. Ludwig and R. Krieg, An analytical quasi-exact method for calculating eigenvibrations of thin circular cylindrical shella, J. Sound Vibr. 74 (1981) 155-174.

[6] H. Mosinger, Investigation of blowdown problems with the computer code DRIX-2i, Nucl. Sci. Engrg. 76 (1980) 89-102.
[7] U. Schumann and J. Benner, Homogenized model for fluid-structure interactions in a pressurized water resctor core, in: Proc. 6th Internat. Conf, on Structural Mechanics in Reactor Technology, Paria, Aug. 1981, paper BS/7.

[8] J. Benner, to be published (1983).

[9] U. Schumann, Impacts and fuid-structure interactions in proseurized water reactor safety andysic, Nucl. Engrg. Des. 69 (1982) 313-326.

[10] L. Wolf (Ed.): Devign report for the HDR-RPV-I blowdown experiments V31.2, V32, V33 and V34. HDR Sicherheitsprogranum, Kemforschungezentrum Karlsruhe. PHDR-Arbeitsbericht No. 3.243/81.

[11] HDR Sicherheitsprogramm, Kernforschungszentrum Karleruhe: Veruuchsprotokoll, Blowdown-Versuch Nr. 34 . PHDR-Arbeitsbericht Nr. 3.277/82 (1982).

[12] M. Schall and L. Wolf, HDR Sicherheitsprogramm-Untersuchungen von RDB-Einbauten bei Bruch einer Reaktorkthimittelleitung, Quick Look Report RDB-E V31.2, V32, V33 and V34. Kernforschungszentrum Karisruhe, Techn. Fachbericht PHDR 29.82 (1982), in preparation.

1 A. Ludwig and U. Schumann, Fluici-structure analysis for the HDR blowdown and snapback experiments with FLUX, Nucl. Engrg. Des. 70 (1982) 32i-333.

[14] U. Schumann et al.. Precomputations with FLUX for the German Standard Problem No. 5, Kernforachungszentrum Karlsruhe, KfK 3444 B (1982), in preparation. 